\title{
ỨNG DỤNG BỘ HẤP THỤ MÀNG CHẢY TRÊN CHÙM ỐNG TRÒN NÀ̀M NGANG VÀO MÁY LẠNH HẤP THỤ ĐẾ SẢN XUẤT NƯỚC ĐÁ
}

\author{
NGUYỄN HIẾU NGHĨA, ĐƯỜNG CÔNG TRUYỀN \\ Khoa Công nghệ Nhiệt lạnh, Truờng Đại học Công nghiệp Thành Phố Hồ Chí Minh; \\ nguyenhieunghia@iuh.edu.vn
}

Tóm tắt. Nhằm mục đích phát triển ứng dụng các máy lạnh hấp thụ $\mathrm{NH}_{3}-\mathrm{H}_{2} \mathrm{O}$ tại Việt $\mathrm{Nam}$, một trong những hướng nghiên cứu mấu chốt là sự chọn lựa cấu trúc bộ hấp thụ với mong muốn là sẽ chế tạo được tại Việt Nam mà không cần sự đầu tư công nghệ mới nào. Các quá trình truyền nhiệt-truyền chất xuất hiện giữa dung dịch lỏng và hơi trong bộ hấp thụ dạng màng chảy đã được nghiên cứu lý thuyết và thực nghiệm, chúng tôi làm rõ hơn khả năng ứng dụng của bộ hấp thụ dạng này cho máy lạnh hấp thụ loại liên tục để sản xuất nước đá. Một chuỗi các thí nghiệm xác định nồng độ từ $29,5 \%$ tới 32,5\% để tìm nồng độ dung dịch nạp phù hợp. Các kết quả cho thấy nồng độ nạp phù hợp là $31 \%$ thì hệ số hiệu quả $\mathrm{COP}=0,436$ và hệ số hiệu quả làm lạnh nước muối $\mathrm{COP}_{\mathrm{u}}=0,262$, nhiệt độ trung bình của hơi $\mathrm{NH}_{3}$ rời khỏi bình phát sinh là $\mathrm{t}_{5}$ $=116,5^{\circ} \mathrm{C}$, Nồng độ trung bình của dung dịch loãng và dung dịch đặc lần lượt là $29,14 \%$ và $34,11 \%$.

Từ khóa. Bộ hấp thụ, làm lạnh hấp thụ, máy lạnh hấp thụ.

\section{APPLIED HORIZONTAL ROUND TUBE BANKS FALLING-FILM ABSORBER FOR ABSORPTION REFRIGERATION SYSTEM FOR MAKING ICE}

\begin{abstract}
Aiming to develop the application of $\mathrm{NH}_{3}-\mathrm{H}_{2} \mathrm{O}$ absorption refrigeration system in Vietnam, one of the key research directions is the selection of absorber structure which is expected to be fabricated in Vietnam without demand of new infrastructure investment. After the heat and mass transfers occurring between liquid and vapor in falling film absorber had been studied theoretically and experimentally, we further clarified its suitability when applying this type of absorber in Un-intermittent absorption refrigeration system for making ice. A series of experiments varying the concentration from $29.5 \%$ to $32.5 \%$ was done to look for the suitable intake concentration. The results showed that the suitable intake concentration is $31 \%$ which corresponds to the following properties: the coefficient of performance $\mathrm{COP}=$ 0.436 , the brine refrigeration performance $\mathrm{COP}_{\mathrm{u}}=0.262$, the average temperature of ammonia vapor leaving the generator is $t_{5}=116.5^{\circ} \mathrm{C}$, the average concentrations of weak and strong solution are $29.14 \%$ and $34.11 \%$, respectively.
\end{abstract}

Keywords. Absorber, Absorption refrigeration, Absorption refrigeration system.

\section{GIỚI THIÊU}

Bộ hấp thụ của hệ thống lạnh hấp thụ được biết đến như là thành phần quan trọng nhất của hệ thống về mặt hiệu suất và chi phí [1]. Diện tích truyền nhiệt của bộ hấp thụ chiếm khoảng $40 \%$ tổng diện tích truyền nhiệt của hệ thống $[2,3]$. Chi phí chế tạo hệ thống sẽ giảm đáng kể nếu như diện tích truyền nhiệt của bộ hấp thụ có thể được giảm bớt bằng cách nâng cao hiệu quả truyền nhiệt-truyền chất trong bộ hấp thụ.

Các nghiên cứu quá trình hấp thụ hơi $\mathrm{NH}_{3}$ thường tập trung vào bốn điểm chính: đặc tính của bộ hấp thụ dạng màng lỏng mỏng, tăng đối lưu Marangoni, khuếch tán $\mathrm{NH}_{3}$ vào dung dịch loãng, và đặc tính của bộ hấp thụ dạng bọt. Trong đó, sự hấp thụ dạng màng lỏng, và dạng bọt được thực nghiệm và số hóa như các bộ hấp thụ hoàn chỉnh (xem hình 1). Một số điểm nghiên cứu khác chỉ có tính chất xem xét một khía cạnh đặc biệt nào đó của quá trình hấp thụ hơn là xét cho toàn bộ hấp thụ. 


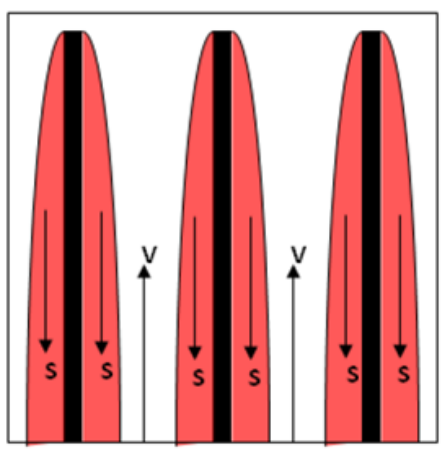

(a) Dạng màng

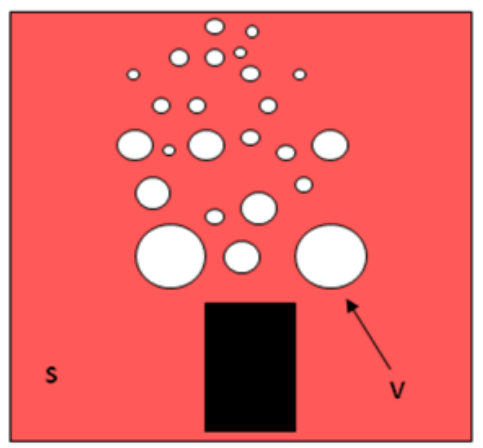

(b) Dạng bọt

Hình 1: Các dạng hấp thụ chính

Nhiều thiết kế dựa vào bộ hấp thụ dạng màng hoặc dạng bọt được nghiên cứu rộng rãi. Mục đích của các nghiên cứu này là để giảm kích thước của bình hấp thụ $\mathrm{NH}_{3}-\mathrm{H}_{2} \mathrm{O}$ nhưng vẫn đảm bảo đặc tính truyền chấttruyền nhiệt tốt.

Bộ hấp thụ dạng màng lỏng thì ổn định khi hoạt động và có hệ số truyền nhiệt cao nên có thể giảm kích thước bề mặt giải nhiệt [4]. Khó khăn của bộ hấp thụ dạng màng là sự phân phối không đều dung dịch loãng, bề mặt giải nhiệt không ướt đều, bề mặt giải nhiệt đứng bị chảy dày. Các vấn đề trên làm cho trở lực truyền chất-truyền nhiệt tăng ở phía dung dịch. Bộ hấp thụ dạng bọt có hệ số truyền chất khá cao nhờ sự phân phối những bọt hơi nhỏ làm cho diện tích bề mặt truyền chất có thể được gia tăng [5]. Khó khăn của bộ hấp thụ dạng bọt là tốc độ truyền nhiệt phía dung dịch thấp, kết cấu phức tạp và chế tạo khó khăn do đòi hỏi công nghệ cao. Sau khi nghiên cứu tổng quan, xem xét điều kiện thực tế, và dựa vào tính khả thi của bộ hấp thụ kiểu màng chảy, bộ hấp thụ kiểu màng chảy trên ống tròn nằm ngang được chọn lựa cho nghiên cứu ứng dụng này.

Hình 2a trình bày sơ đồ bộ hấp thụ dạng màng chảy trên hai tấm vách giải nhiệt. Dung dịch NH3-H2O chảy xuống từ đỉnh của bộ hấp thụ ngược chiều với dòng hơi NH3 chảy từ dưới lên. Trong kết cấu tấm, hiệu suất truyền chất của dạng bọt tốt hơn dạng màng theo tài liệu Ki Bong Lee và cộng sự [4]. Tương tự, hình $2 b$ trình bày sơ đồ bộ hẩp thụ dạng màng chảy trên vách tròn theo tài liệu Kang và cộng sự [6].

Md. Raisul Islam [7] mô tả thực nghiệm và phân tích lý thuyết của các quá trình của các quá trình truyền nhiệt và truyền khối kết hợp diễn ra trong bộ hấp thụ. Dung dịch NH3 loãng từ bộ phân phối được phun lên các ống song song nằm ngang như hình $2 \mathrm{c}$. Tương tự, dung dịch NH3 loãng từ bộ phân phối được phun lên các ống so le nằm ngang như hình $2 \mathrm{~d}$ theo tài liệu Srinivas Garimella và cộng sự [8].

Goel, N., Goswami, D., Y. [9] cố gắng giảm kích thước bộ hấp thụ. Thiết kế dựa trên đặc tính diện tích mặt tiếp xúc lỏng hơi lớn và bề mặt ướt tốt. Các ống giải nhiệt được ghép song song và kết nối lưới với nhau như hình 2e. Tương tự, dung dịch $\mathrm{NH} 3$ loãng từ ống phân phối nhiễu lên các ống song song nằm ngang như hình $2 \mathrm{f}$. Bộ hấp thụ kiểu màng có kết cấu như hình $2 \mathrm{f}$ được chọn lựa vì có kết cấu đơn giản, hiệu suất truyền nhiệt tốt, có thể chế tạo được theo điều kiện công nghệ hiện có tại Việt Nam mà không cần phải nhập khẩu dây chuyền sản xuất mới.

Bộ hấp thụ này được gắn cùng với các bộ phận khác để tạo nên một máy lạnh hấp thụ hoàn chỉnh hoạt động theo điều kiện môi trường tại Việt Nam trong phạm vi nhiệt độ bay hơi của môi chất lạnh trong bộ bay hơi, ngưng tụ của môi chất lạnh trong bình ngưng tụ, hấp thụ của dung dịch ra khỏi bộ hấp thụ, phát sinh của dung dịch trong bình phát sinh lần lượt là $(-20 \mathrm{oC}<$ te $<-10 \mathrm{oC}, 30 \mathrm{oC}<\mathrm{tc}<35 \mathrm{oC}, 30 \mathrm{oC}<\mathrm{ta}<38 \mathrm{oC}$, $95 \mathrm{oC}<\operatorname{tg}<125 \mathrm{oC})$ để xác định tính ổn định của máy.

Từ thực tế về dải năng suất sản xuất nước đá hiện có trên thị trường và khả năng đáp ứng của bơm dung dịch, tác giả đã đề xuất ứng dụng cho máy lạnh hấp thụ có dải năng suất lạnh trung bình từ $30 \div 60 \mathrm{~kW}$, năng suất làm đá từ $5 \div 10$ tấn/ngày (khoảng $200 \mathrm{~kg} / \mathrm{mẻ}$ ). Đối với dải năng suất lạnh này, năng suất của bình hấp thụ tương ứng ở trong khoảng từ $52 \div 104 \mathrm{~kW}$.

Bộ hấp thụ có dạng hình hộp nên việc bố trí các chùm ống song song rất thuận tiện, nó thuận lợi và tốt cho vấn đề truyền nhiệt và truyền chất. Bộ hấp thụ hoạt động ở áp suất thấp hơn áp suất của bộ bay hơi một chút khoảng 2 bar nên vấn đề về an toàn thiết bị khi vận hành không đáng ngại. Hơn nữa, Bộ hấp thụ đã 
được tính kiển tra về áp lực và kiểm tra bền với hệ số an toàn rất cao có thể chịu áp lực lên bằng áp lực của Bình ngưng tụ (20 bar) để đảm bảo an toàn cho hệ thống.

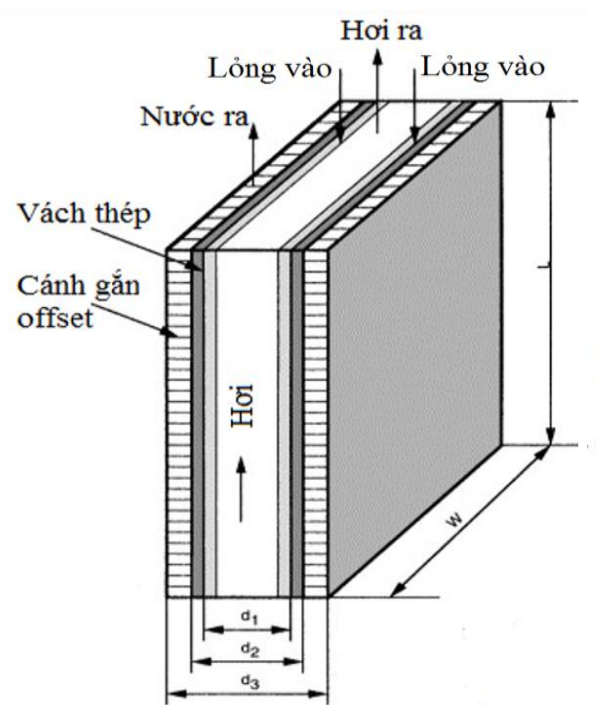

a. Màng chảy trên vách phẳng
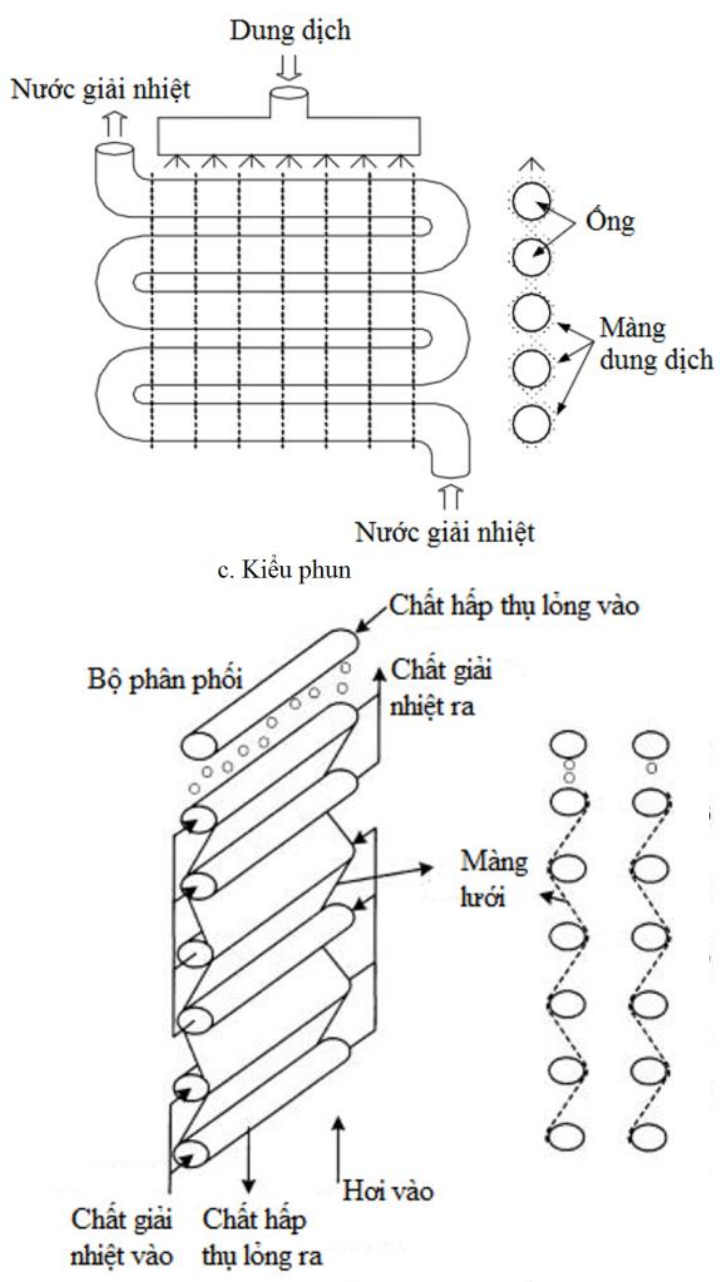

e. Ghép song song có nối lưới

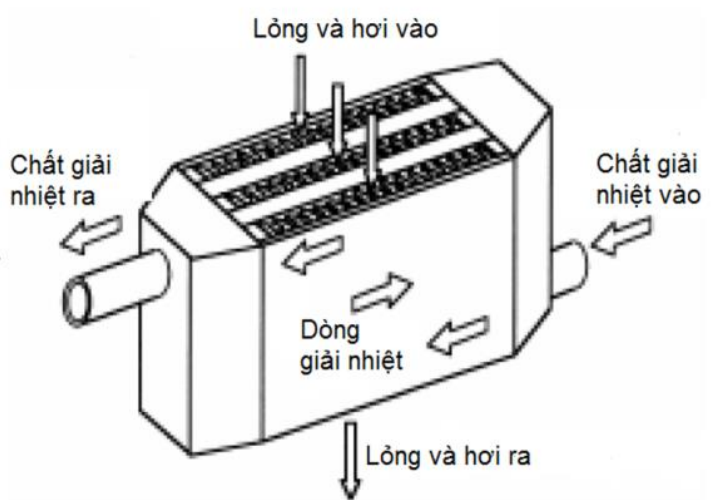

b. Màng chảy trên vách tròn
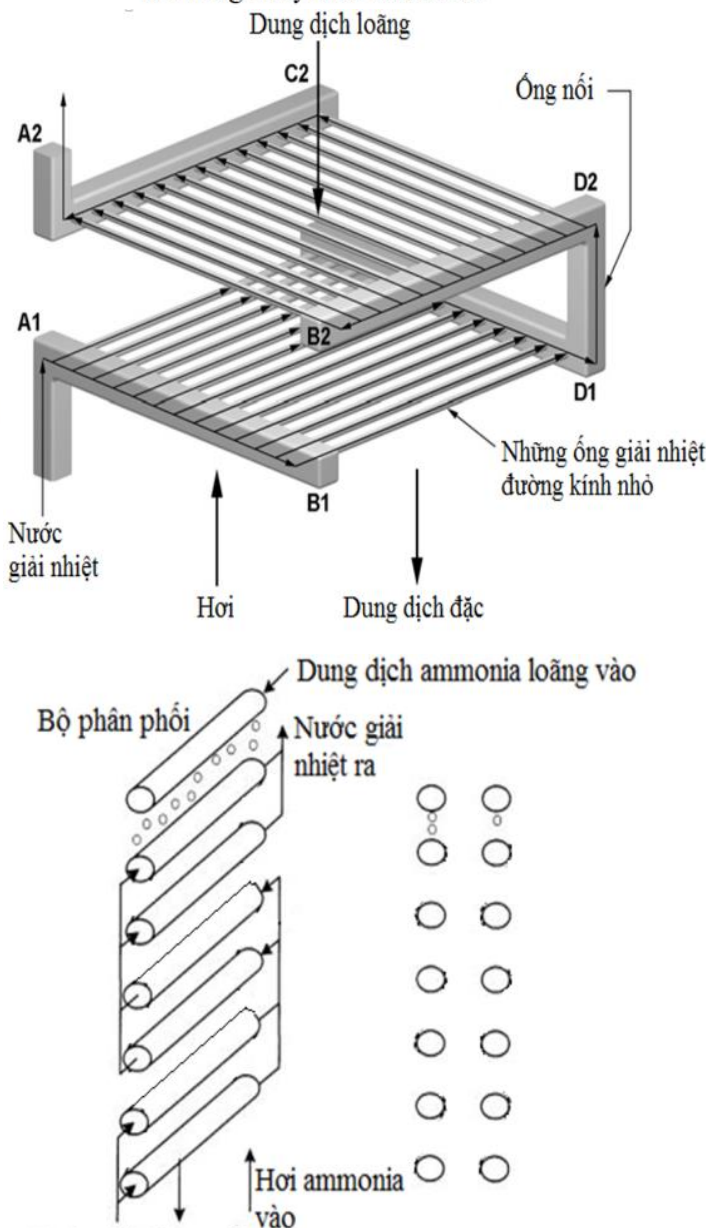

Nước giäi Dung dịch

nhiệt vào ammonia đặc ra

f. Ghép song song các tầng ống trơn

Hình 2: Các bình hấp thụ dạng màng chính 


\section{MÔ HÌNH TOÁN CỦA MÁY LẠNH HẤP THỤ \\ 2.1 Mô tả hệ thống}

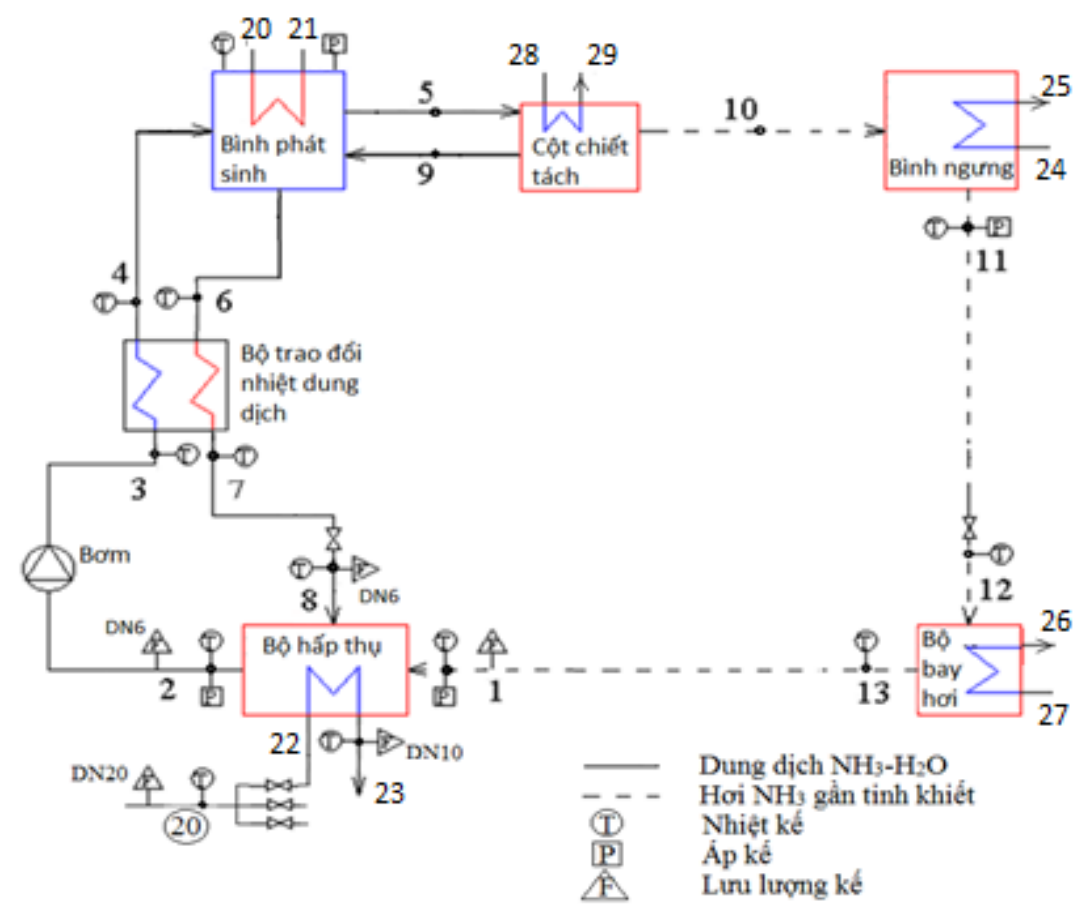

Hình 2: Sơ đồ thiết kế hệ thống lạnh NH3-H2O

Hình 3 trình bày sơ đồ nguyên lý của lạnh hấp thụ $\mathrm{NH}_{3}-\mathrm{H}_{2} \mathrm{O}$ một cấp được chọn lựa để thiết kế. Hơi áp suất thấp và nhiệt độ thấp (hầu hết là $\mathrm{NH}_{3}$ nguyên chất) ở trạng thái 13 rời khỏi bộ bay hơi, đi vào bộ hấp thụ ở trạng thái 1 . Môi chất lạnh này được hấp thụ bởi dung dịch loãng đến từ van giảm áp ở trạng thái 8 . Nhiệt của sự hấp thụ $\left(\mathrm{Q}_{\mathrm{a}}\right)$ được lấy đi nhờ nước giải nhiệt. Kế tiếp dung dịch đặc sẽ rời khỏi bộ hấp thụ ở trạng thái 2 và được bơm dung dịch tăng lên áp suất phát sinh ở trạng thái 3 . Dung dịch đặc áp suất cao này sau đó được gia nhiệt trong bộ trao đổi nhiệt dung dịch và ra thành trạng thái 4 ; tiếp tục vào bình phát sinh và bộ trao đổi nhiệt lượng, khối lượng với hơi sinh ra trong bình phát sinh. Trong bình phát sinh, nhiệt được cấp vào dung dịch $\left(\mathrm{Q}_{\mathrm{g}}\right)$ để sinh hơi $\mathrm{NH}_{3}$ và nước bị kéo theo. Phần nước bị kéo theo này trao đổi nhiệt lượng và khối lượng với dung dịch đặc chảy từ trên xuống. Suốt quá trình này, nhiệt độ của hơi và nước bị kéo theo giảm xuống. Hơi này ở trạng thái 5 sau đó đi vào bộ hồi lưu. Tại đây, hơi nước trong hỗn hợp sẽ bị tách ra bằng cách ngưng tụ - giải nhiệt. Quá trình giải nhiệt $\left(\mathrm{Q}_{\mathrm{d}}\right)$ được đưa ra ngoài qua nước giải nhiệt trong bộ hồi lưu. Kết quả là hơi sẽ đạt trạng thái 10 hầu hết là hơi $\mathrm{NH}_{3}$ (chiếm hơn $99 \%$ khối lượng) sau đó vào bình ngưng tụ và ngưng tụ giải nhiệt $\left(\mathrm{Q}_{\mathrm{c}}\right)$ cho nước giải nhiệt. Lỏng ngưng tụ ở trạng thái 11 sau đó qua van tiết lưu để thành trạng thái 12. Môi chất lạnh vào bộ bay hơi thu nhiệt của môi trường cần làm lạnh $\left(\mathrm{Q}_{\mathrm{e}}\right)$ và ra khỏi bộ bay hơi ở trạng thái 13 . Từ đây, nó vào bộ quá lạnh để hoàn tất chu trình làm lạnh. Bây giờ, nước ngưng trong bộ hồi lưu ở trạng thái 9 chảy xuống từ ống tách cùng với dung dịch đặc trở về từ bộ hấp thụ cùng về bình phát sinh thực hiện trao đổi nhiệt và trao đổi chất sinh hơi $\mathrm{NH}_{3}$ bay lên. Dung dịch loãng nóng ở trạng thái 6 đi vào bộ trao đổi nhiệt dung dịch nguội đi thành trạng thái 7 , sau đó qua van giảm áp dung dịch để thành trạng thái 8 vào bộ hấp thụ kết thúc chu trình.

Với cách bố trí 14 dụng cụ đo nhiệt độ, 4 dụng cụ đo áp suất, 5 dụng cụ đo lưu lượng dòng lỏng và 01 dụng cụ đo lưu lượng dòng hơi tại 12 điểm trạng thái như ở hình 3 thì tất cả 12 điểm trạng thái tìm được theo tính toán lý thuyết của máy lạnh hấp thụ đều được kiểm chứng từ đo đạc thực tế.

\subsection{Mô tả toán học}

Mô hình toán được phát triển để phân tích hiệu suất của hệ thống thử nghiệm tính toán điển hình. Nhiệt độ và áp suất của lưu chất làm việc dựa trên các giá trị thiết kế. Các mô hình nhiệt động của các bộ phận đảm bảo cân bằng năng lượng và khối lượng và một chương trình mô phỏng được phát triển để phân tích chu trình. Sự phân tích thể tích kiểm tra của từng bộ phận (bình phát sinh, bình hồi lưu, bình ngưng tụ, bộ bay 
hơi, bộ hấp thụ, bình trao đổi nhiệt dung dịch, bơm dung dịch, van tiết lưu dung dịch loãng, và van tiết lưu môi chất lạnh).

\section{Tốc độ truyền nhiệt (Qi)}

$$
\begin{aligned}
& Q_{i}=\sum_{\alpha=1}^{j}\left[\left(m_{\alpha} \cdot i\right)_{\text {in }}+\left(m_{\alpha} \cdot i_{\alpha}\right)_{\text {out }}\right] \\
& \sum_{\alpha=1}^{i}\left(m_{\alpha}\right)_{\text {in }}=\sum_{\alpha=1}^{j}\left(m_{\alpha}\right)_{\text {out }}
\end{aligned}
$$

Trong đó, i Entanpy riêng (kJ/kg); m Lưu lượng khối lượng $(\mathrm{kg} / \mathrm{s})$

Các phương trình cân bằng năng lượng, cân bằng lưu lượng khối lượng giữa giữa các dòng môi chất lạnh, độ chênh nhiệt độ trung bình log của bộ hấp thụ dùng để tính diện tích trao đổi nhiệt của từng bộ phận trong hệ thống.

\section{Bộ hấp thụ}

Bình phát sinh

$$
\begin{aligned}
& m_{8} \cdot i_{8}+m_{1} \cdot i_{1}-m_{2} \cdot i_{2}=m_{22} \cdot\left(i_{23}-i_{22}\right) \\
& m_{2} \cdot C_{2}=m_{8} \cdot C_{8}+m_{1} \cdot C_{1} \\
& \operatorname{LMTD}_{a}=\frac{\left(T_{8}-T_{23}\right)-\left(T_{2}-T_{22}\right)}{\ln \left(\frac{T_{8}-T_{23}}{T_{2}-T_{22}}\right)}
\end{aligned}
$$

$$
\begin{aligned}
& m_{4} \cdot C_{4}+m_{9} \cdot C_{9}=m_{5} \cdot C_{5}-m_{6} C_{6} \\
& m_{5} \cdot i_{5}+m_{6} \cdot i_{6}-m_{4} \cdot i_{4}-m_{9} \cdot i_{9}=m_{20} \cdot\left(i_{20}-i_{21}\right) \\
& \operatorname{LMTD}_{d}=\frac{\left(T_{20}-T_{6}\right)-\left(T_{21}-T_{4}\right)}{\ln \left(\frac{T_{20}-T_{6}}{T_{21}-T_{4}}\right)}
\end{aligned}
$$

Bình ngưng tụ

\section{Bộ bay hoi}

$$
\begin{gathered}
m_{10} \cdot\left(i_{10}-i_{11}\right)=m_{24} \cdot\left(i_{25}-i_{24}\right) \\
\operatorname{LMTD}_{c}=\frac{\left(T_{10}-T_{25}\right)-\left(T_{11}-T_{24}\right)}{\ln \left(\frac{T_{10}-T_{25}}{T_{11}-T_{24}}\right)}
\end{gathered}
$$

\section{Van tiết lưu}

$$
\begin{aligned}
& m_{12} \cdot\left(i_{13}-i_{12}\right)=m_{26} \cdot\left(i_{26}-i_{27}\right) \\
& \operatorname{LMTD}_{e}=\frac{\left(T_{26}-T_{13}\right)-\left(T_{27}-T_{12}\right)}{\ln \left(\frac{T_{26}-T_{13}}{T_{27}-T_{12}}\right)}
\end{aligned}
$$

Van tiết lưu có tác dụng làm giảm áp và chia thành hai mức áp suất khác nhau. Không có sự trao đổi nhiệt của lưu chất làm việc tại van tiết lưu. Entanpy của lưu chất làm việc trước và sau van là không đổi. Quá trình thay đổi áp suất giữa hai điểm của van tiết lưu không có sự thay đổi lưu lượng khối lượng và quá trình được xem là đoạn nhiệt, thể tích có thể thay đổi khi lưu chất có một lượng nhỏ bị hóa hơi (flashing).

Bộ trao đổi nhiệt dung dịch

\section{Bơm dung dịch}

$$
\begin{aligned}
& \mathrm{T}_{7}=\mathrm{T}_{3} \cdot \eta_{\text {shx }}+\mathrm{T}_{6} \cdot\left(1-\eta_{\text {shx }}\right) \\
& \mathrm{m}_{3} \cdot\left(\mathrm{i}_{4}-\mathrm{i}_{3}\right)=\mathrm{m}_{6} \cdot\left(\mathrm{i}_{6}-\mathrm{i}_{7}\right) \\
& \operatorname{LMTD}_{\mathrm{shx}}=\frac{\left(\mathrm{T}_{6}-\mathrm{T}_{4}\right)-\left(\mathrm{T}_{7}-\mathrm{T}_{3}\right)}{\ln \left(\frac{\mathrm{T}_{6}-\mathrm{T}_{4}}{\mathrm{~T}_{7}-\mathrm{T}_{3}}\right)}
\end{aligned}
$$

Công suất cần thiết để chuyển lưu lượng khối lượng dung dịch $\mathrm{m}_{2}$ từ áp suất $\mathrm{P}_{2}$ lên áp suất $\mathrm{P}_{3}$, hiệu suất bơm là $\eta_{\mathrm{p}}$ :

$$
W_{p}=\frac{m_{2} \cdot v_{2} \cdot\left(P_{3}-P_{2}\right)}{\eta_{p}}
$$


Quá trình bơm là đẵng entropy, entanpy của dung dịch sẽ tăng nhẹ tại đầu đẩy. Vì thế, cân bằng năng lượng qua bơm dung dịch có thể tính bằng:

\section{Cột chiết tách}

$$
m_{2} \cdot i_{2}+W_{p}=m_{3} \cdot i_{3}
$$

$$
\begin{aligned}
& m_{5} \cdot i_{5}-m_{9} \cdot i_{9}-m_{10} \cdot i_{10}=m_{28} \cdot\left(i_{29}-i_{28}\right) \\
& \text { LMTD }_{\text {rec }}=\frac{\left(T_{5}-T_{29}\right)-\left(T_{10}-T_{28}\right)}{\ln \left(\frac{T_{5}-T_{29}}{T_{10}-T_{28}}\right)}
\end{aligned}
$$

Hoạt động của hệ thống được đánh giá theo phương trình hệ số entanpy như sau [11]:

$$
\chi=\left(i-i_{l}\right) /\left(i_{v}-i_{l}\right)
$$

Trong đó, $i$ là entanpy của lưu chất theo áp suất cho trước; $i_{1}$ và $i_{v}$ lần lượt là entanpy của lưu chất lỏng bão hòa và hơi bão hòa tại cùng áp suất. Từ định nghĩa $\chi$, có thể biết được trạng thái của lưu chất như sau: $\chi<$ 0 là quá lạnh, $\chi=0$ là lỏng bão hòa, $0<\chi<1$ là hai pha, $\chi=1$ là hơi bão hòa, và $\chi>1$ là quá nhiệt.

\section{Hiệu suất của hệ thống}

Hệ số hiệu quả nhiệt của máy lạnh COP là tỉ số giữa công suất nhiệt thu được từ môi trường cần làm lạnh thông qua bộ bay hơi so với công suất nhiệt cấp vào bình phát sinh để vận hành chu trình.

Trong đó:

$$
\mathrm{COP}=\frac{\mathrm{Q}_{\mathrm{e}}}{\mathrm{Q}_{\mathrm{g}}}
$$

$\mathrm{Q}_{\mathrm{e}}$ Công suất lạnh $(\mathrm{kW})$

$\mathrm{Q}_{\mathrm{g}}$ Công suất nhiệt cấp vào bình phát $\sinh (\mathrm{kW})$

Hiệu suất làm lạnh dung dịch nước muối

Hệ số hiệu quả làm lạnh nước muối của máy lạnh $\mathrm{COP}_{\mathrm{u}}$ là tỉ số giữa nhiệt lượng bay hơi của $\mathrm{NH}_{3}$ để làm lạnh nước muối so với nhiệt lượng cấp vào bình phát sinh để vận hành chu trình.

Trong đó:

$$
C O P_{u}=\frac{\mathrm{Q}_{\mathrm{NaCl}}}{\mathrm{Q}_{\mathrm{g} J}}
$$

$\mathrm{Q}_{\mathrm{NaCl}}$ Nhiệt lượng bay hơi của $\mathrm{NH}_{3}$ để làm lạnh nước muối $(\mathrm{kJ})$

$\mathrm{Q}_{\mathrm{g} \_\mathrm{J}}$ Nhiệt lượng cấp vào bình phát $\sinh (\mathrm{kJ})$

Khi thiết kế hệ thống, bình ngưng tụ và bộ hấp thụ nên được thiết kế hoạt động ở $3 \div 5{ }^{\circ} \mathrm{C}$ cao hơn nhiệt độ môi trường (nhiệt độ nước giải nhiệt) [21].

\section{KẾT QUẢ VÀ THẢO LUẬN}

\section{1 Đánh giá độ sai lệch của bộ hấp thụ}

Tính cho điều kiện mồi trường tại TP. Hồ Chí Minh và nguồn nhiệt cấp vào đáp ứng được nhu cầu làm nước đá. Dữ liệu đầu vào lấy từ thực nghiệm: nhiệt độ ngưng tụ của hơi $\mathrm{NH}_{3}\left(\mathrm{t}_{\mathrm{c}}=34,5^{\circ} \mathrm{C}\right)$, nhiệt độ hấp thụ của dung dịch $\mathrm{NH}_{3}-\mathrm{H}_{2} \mathrm{O}$ đậm đặc rời khỏi bộ hấp thụ $\left(\mathrm{t}_{\mathrm{a}}=36,6^{\circ} \mathrm{C}\right)$, nhiệt độ bay hơi của $\mathrm{NH}_{3}$ trong bộ bay hơi $\left(\mathrm{t}_{\mathrm{e}}=-19^{\circ} \mathrm{C}\right)$, công suất điện cấp vào Psupply $=3,76 \mathrm{~kW}$, nhiệt độ phát sinh của dung dịch trong bình phát sinh $t_{\mathrm{g}}=120^{\circ} \mathrm{C}$. Tính chất nhiệt động tại các trạng thái khác nhau của hệ thống được thể hiện trong bảng 1 .

Bảng 1: Các điểm trạng thái của máy lạnh hấp thụ thiết kế

\begin{tabular}{|l|l|l|l|l|l|l|l|l|l|}
\hline Điểm & $\mathbf{N H} \mathbf{H}_{3}-\mathrm{H}_{2} \mathbf{O}$ & $\mathbf{p}(\mathbf{b a r})$ & $\mathbf{t}\left({ }^{\mathbf{0}} \mathbf{C}\right)$ & $\mathbf{C}(\mathbf{\%})$ & $\mathbf{i}(\mathbf{k J} / \mathbf{k g})$ & $\mathbf{v}(\mathbf{l} / \mathbf{p})$ & $\mathbf{m} \mathbf{( k g / s )}$ & $\chi$ & Trạng thái \\
\hline 1 & $\mathrm{NH}_{3}$ & 1,6 & 17,5 & 99,4 & 1333,3 & 11,34 & 0,0013 & 1,064 & Hơi quá nhiệt \\
\hline 2 & $\mathrm{NH}_{3}-\mathrm{H}_{2} \mathrm{O}$ & 1,5 & 36 & 32,5 & $-99,3$ & 1,31 & 0,0191 & 0 & Lỏng bão hòa \\
\hline 3 & $\mathrm{NH}_{3}-\mathrm{H}_{2} \mathrm{O}$ & 14 & 40,1 & 32,5 & $-80,4$ & 1,31 & 0,0191 & $-0,159$ & Lỏng quá lạnh \\
\hline 4 & $\mathrm{NH}_{3}-\mathrm{H}_{2} \mathrm{O}$ & 13,93 & 99,1 & 32,5 & 185,4 & 1,31 & 0,0191 & $-0,025$ & Lỏng quá lạnh \\
\hline 5 & $\mathrm{NH}_{3}-\mathrm{H}_{2} \mathrm{O}$ & 13,9 & 118 & 90 & 1611,4 & 12,6 & 0,0015 & 1,139 & Hơi quá nhiệt \\
\hline 6 & $\mathrm{NH}_{3}-\mathrm{H}_{2} \mathrm{O}$ & 13,87 & 112,5 & 27,8 & 276,4 & 1,215 & 0,0179 & 0 & Lỏng bão hòa \\
\hline
\end{tabular}



LẠH HẤP THỤ ĐỂ SẢN XUÂT NƯỚC ĐÁ

\begin{tabular}{|l|l|l|l|l|l|l|l|l|l|}
\hline 7 & $\mathrm{NH}_{3}-\mathrm{H}_{2} \mathrm{O}$ & 13,8 & 48,8 & 27,8 & $-9,65$ & 1,215 & 0,0179 & $-0,162$ & Lỏng quá lạnh \\
\hline 8 & $\mathrm{NH}_{3}-\mathrm{H}_{2} \mathrm{O}$ & 1,62 & 49 & 27,8 & $-9,65$ & 1,215 & 0,0179 & $-0,162$ & Lỏng quá lạnh \\
\hline 9 & $\mathrm{H}_{2} \mathrm{O}$ & 13,9 & 107,8 & 0 & 448 & 0,0133 & 0,0002 & 0 & Lỏng bão hòa \\
\hline 10 & $\mathrm{NH}_{3}$ & 13,85 & 107,8 & 99,4 & 1496,6 & 11,34 & 0,0013 & 1,171 & Hơi quá nhiệt \\
\hline 11 & $\mathrm{NH}_{3}$ & 13,8 & 30,2 & 99,4 & 130,9 & 11,34 & 0,0013 & 0 & Lỏng bão hòa \\
\hline 12 & $\mathrm{NH}_{3}$ & 1,73 & $-14,3$ & 99,4 & 130,9 & 11,34 & 0,0013 & 0,181 & Hai pha \\
\hline 13 & $\mathrm{NH}_{3}$ & 1,62 & -20 & 99,6 & 1245,5 & 58,5 & 0,0013 & 1 & Hơi bão hòa \\
\hline
\end{tabular}

Qua các bộ trao đổi nhiệt, entanpy i của các điểm trạng thái sau mang dấu âm khi lượng nhiệt của dòng đó được lấy đi lớn hơn entanpy của điểm trạng thái phía trước đó. Ví dụ: Dung dịch $\mathrm{NH}_{3}-\mathrm{H}_{2} \mathrm{O}$ loãng ở nhiệt độ cao và áp suất cao tại điểm 6 được dòng dung dịch $\mathrm{NH}_{3}-\mathrm{H}_{2} \mathrm{O}$ đặc nhiệt độ thấp và áp suất cao thu nhiệt, Lượng nhiệt này bị thu lớn hơn entanpy của điểm 6 nên giá entanpy ở điểm 7 mang dấu âm.

Công suất của các bộ phận được tính toán: bay hơi, ngưng tụ, hấp thụ, phát sinh, cột chiết tách, công suất bơm dung dịch, hệ số hiệu quả nhiệt của hệ thống lần lượt là $\mathrm{Q}_{\mathrm{e}}=1,52 \mathrm{~kW} ; \mathrm{Q}_{\mathrm{c}}=1,727 \mathrm{~kW} ; \mathrm{Q}_{\mathrm{a}}=3,412$ $\mathrm{kW} ; \mathrm{Q}_{\mathrm{g}}=3,762 \mathrm{~kW} ; \mathrm{Q}_{\mathrm{d}}=0,41 \mathrm{~kW} ; \mathrm{Q}_{\mathrm{p} \_ \text {out }}=0,362 \mathrm{~kW} ; \mathrm{COP}=0,413$. Bội số tuần hoàn $\mathrm{f}=15,1$. Thí nghiệm được thực hiện cho máy lạnh hấp thụ hoàn chỉnh và hoạt động ổn định. Theo tính toán hệ thống, Công suất nhiệt của bộ hấp thụ $\mathrm{Q}_{\mathrm{a} \_ \text {compute }}=3,412 \mathrm{~kW}$.

Công suất nhiệt của bộ hấp thụ đo đạc được cũng chính là công suất mà dòng nước giải nhiệt mang đi $\mathrm{Q}_{\mathrm{a} \text { _cooling }}=\mathrm{m}_{\mathrm{w}} * \mathrm{C}_{\mathrm{p}} * \Delta \mathrm{t}_{\mathrm{w}}=16,4 * 0,995 * 4,174 *(33,5-30,7) / 60=3,084 \mathrm{~kW}$. Công suất này bao gồm cả phần công suất nhiệt của dòng hơi đang ở nhiệt độ thấp đi vào bộ hấp thụ $18,5^{\circ} \mathrm{C}$ lên đến nhiệt độ dung dịch đậm đặc ra khỏi bộ hấp thụ $35,8^{\circ} \mathrm{C}$; nhiệt dung riêng của dòng hơi $\mathrm{NH}_{3} \mathrm{C}_{\mathrm{p} \_a m m o}=2,72 \mathrm{~kJ} /(\mathrm{kg} . \mathrm{K})$; lưu lượng dòng hơi $\mathrm{NH}_{3} \mathrm{~m}_{\text {ammo }}=1,82 \mathrm{~g} / \mathrm{s}$ là $\mathrm{Q}_{\mathrm{a} \_ \text {ammo }}=$ mammo $^{*} \mathrm{C}_{\mathrm{p}_{\mathrm{ammo}}} * \mathrm{t}_{\mathrm{ammo}}=1,82 * 2,72 *(36-17,5) * 0,001=0,091$ $\mathrm{kW}$. Vì thế, $\mathrm{Q}_{\mathrm{a} \_ \text {meas }}=\mathrm{Q}_{\mathrm{a} \_ \text {cooling }}+\mathrm{Q}_{\mathrm{a} \_ \text {ammo }}=3,270 \mathrm{~kW}$.

Sai số giữa tính toán hệ thống $\mathrm{Q}_{\mathrm{a} \_}$compute $\mathrm{so}$ với kết quả thực nghiệm $\mathrm{Q}_{\mathrm{a} \_m e a s}$ là 4,3\%.

\section{2 Đánh giá hiệu quả}

Các kêt quả của 14 thí nghiệm $(\mathrm{TN})$ được tổng kết trong bảng 2 . $\mathrm{COP} / \mathrm{COP}_{\mathrm{u}}$ của các thí nghiệm được tính cho 6 giai đoạn từ lúc nhiệt độ nước muối tại nhiệt độ môi trường xuống $20^{\circ} \mathrm{C}\left(\mathrm{t}_{\mathrm{NaCl}} \geq 20^{\circ} \mathrm{C}\right)$; từ 20 ${ }^{\circ} \mathrm{C}>\mathrm{t}_{\mathrm{NaCl}} \geq 10^{\circ} \mathrm{C} ; 10^{\circ} \mathrm{C}>\mathrm{t}_{\mathrm{NaCl}} \geq 0{ }^{\circ} \mathrm{C} ; 0^{\circ} \mathrm{C}>\mathrm{t}_{\mathrm{NaCl}} \geq-10{ }^{\circ} \mathrm{C} ;-10{ }^{\circ} \mathrm{C}>\mathrm{t}_{\mathrm{NaCl}} \geq \mathrm{t}_{\text {lim }}{ }^{\circ} \mathrm{C} ; \mathrm{t}_{\text {lim }}>\mathrm{t}_{\mathrm{NaCl}}$. Giai đoạn $\mathrm{t}_{\mathrm{NaCl}}$ $\geq 20^{\circ} \mathrm{C}$, máy lạnh hấp thụ đang được điều chỉnh chế độ hoạt động và chưa hoạt động ốn định nên không tính giai đoạn này vào hệ số hiệu quả $\mathrm{COP}$ và $\mathrm{COP}_{\mathrm{u}}$. Nhiệt độ giới hạn của dung dịch nước muối tlim là nhiệt độ thấp nhất của dung dịch nước muối còn có thể giảm xuống mà chưa bị mất ổn định. Nếu máy lạnh hấp thụ vẫn tiếp tục hoạt động nhiệt độ dung dịch nước muối có thể giảm thấp hơn nhưng rất chậm và không ổn định nên giai đoạn này $\left(\mathrm{t}_{\mathrm{lim}}>\mathrm{t}_{\mathrm{NaCl}}\right)$ cũng không được tính vào hệ số hiệu quả $\mathrm{COP}$ và $\mathrm{COP}$. Vậy, hệ số hiệu quả $\mathrm{COP}$ và $\mathrm{COP}$ únh từ lúc nhiệt độ nước muối đạt $20^{\circ} \mathrm{C}$ xuống $\mathrm{t}_{\mathrm{im}}$ của các thí nghiệm $20^{\circ} \mathrm{C}>\mathrm{t}_{\mathrm{NaCl}}$ $\geq t_{\lim }{ }^{\circ} \mathrm{C}$.

Dung dịch loãng và dung dịch đặc được lấy mẫu liên tục khi máy lạnh hấp thụ đã hoạt động ổn định. Sau đó, các mẫu này được làm lạnh và chuyển tới phòng thí nghiệm của khoa Hóa trường ĐH Công nghiệp để đo nồng độ. Trong giai đoạn làm thí nghiệm, đã đo hơn 100 mẫu.

Dùng biến tầng để điều chỉnh bơm dung dịch phù hợp với lưu lượng dung dịch loãng và hơi $\mathrm{NH}_{3}$ vào Bộ hấp thụ nhờ kính xem dung dịch trong bộ hấp thụ và các dụng cụ đo lưu lượng dung dịch đặc ra khỏi Bình hấp thụ, lưu lượng dung dịch loãng và lưu lượng hơi vào Bình hấp thụ.

Bảng 2: $\mathrm{COP} / \mathrm{COP}_{\mathrm{u}}$ của các thí nghiệm

\begin{tabular}{|c|c|c|c|c|c|c|c|c|}
\hline TN & $\begin{array}{l}\mathrm{C}_{\mathrm{i}} \\
(\%)\end{array}$ & $\begin{array}{l}\mathrm{V}_{8} / \mathrm{V}_{13} / \\
\mathrm{V}_{2},(\mathrm{l} / \mathrm{p})\end{array}$ & $\begin{array}{l}20>t_{\mathrm{NaC}} \\
\geq 10 \\
\left({ }^{o} C\right)\end{array}$ & $\begin{array}{l}\mathbf{1 0}>\mathrm{t}_{\mathrm{NaC}} \\
\mathrm{l} \geq \mathbf{0}, \\
\left({ }^{\circ} \mathrm{C}\right)\end{array}$ & $\begin{array}{l}0>t_{\mathrm{NaCl}} \\
\geq-10 \\
\left({ }^{o} \mathrm{C}\right)\end{array}$ & $\begin{array}{l}- \\
10>t_{\mathrm{NaC}} \\
\geq \mathbf{t}_{\mathrm{lim}} \\
\left({ }^{o} \mathrm{C}\right)\end{array}$ & $\begin{array}{l}20>t_{\mathrm{NaCl}} \\
\geq \mathrm{t}_{\mathrm{lim}}, \\
\left({ }^{\circ} \mathrm{C}\right)\end{array}$ & Ghi chú \\
\hline 1 & 29,5 & $\begin{array}{l}1,39 / \\
81,72 / 1,36\end{array}$ & $\begin{array}{l}0,393 / \\
0,169\end{array}$ & $\begin{array}{l}0,406 / \\
0,134\end{array}$ & $\begin{array}{l}0,406 / \\
0,17\end{array}$ & $\begin{array}{l}0,405 / \\
0,237\end{array}$ & $\begin{array}{l}0,403 / \\
\mathbf{0 , 1 7 8}\end{array}$ & $\begin{array}{l}\mathrm{t}_{\text {lim }}=-17^{\circ} C ; \mathrm{V}_{8} \text { thấp và } \mathrm{V}_{13} \\
\text { cao. }(4 / 08 / 2016)\end{array}$ \\
\hline 2 & 29,5 & $\begin{array}{l}0,65 / \\
92,21 / 1,11\end{array}$ & $\begin{array}{l}0,453 / \\
0,26\end{array}$ & $\begin{array}{l}0,447 / \\
0,216\end{array}$ & $\begin{array}{l}0,432 / \\
0,13\end{array}$ & $\mathrm{x}$ & $\begin{array}{l}0,444 / \\
\mathbf{0 , 2 0 2}\end{array}$ & $\begin{array}{l}\mathrm{t}_{\lim }=-9^{\circ} C ; \mathrm{V}_{8} \text { rất thấp và } \\
\mathrm{V}_{13} \text { rất cao. }(6 / 08 / 2016)\end{array}$ \\
\hline
\end{tabular}



LẠNH HẤP THỤ ĐỂ SẢN XUẤT NƯỚC ĐÁ

\begin{tabular}{|c|c|c|c|c|c|c|c|c|}
\hline 3 & 29,5 & $\begin{array}{l}0,53 / \\
86,43 / 0,08\end{array}$ & $\begin{array}{l}0,431 / \\
0,22\end{array}$ & $\begin{array}{l}0,427 / \\
0,195\end{array}$ & $\begin{array}{l}0,423 / \\
0,162\end{array}$ & $\begin{array}{l}0,422 / \\
0,088\end{array}$ & $\begin{array}{l}0,425 / \\
\mathbf{0 , 1 6 6}\end{array}$ & $\begin{array}{l}t_{\lim }=-14^{\circ} C ; \mathrm{V}_{8} \text { rất thấp và } \\
\mathrm{V}_{13} \text { cao. }(10 / 08 / 2016)\end{array}$ \\
\hline 4 & 30 & $\begin{array}{l}0,54 / \\
83,28 / 11,9\end{array}$ & $\begin{array}{l}0,45 / \\
0,228\end{array}$ & $\begin{array}{l}0,449 / \\
0,179\end{array}$ & $\begin{array}{l}0,438 / \\
0,144\end{array}$ & $\begin{array}{l}0,425 / \\
0,113\end{array}$ & $\begin{array}{l}0,441 / \\
\mathbf{0 , 1 6 7}\end{array}$ & $\begin{array}{l}t_{\lim }=-16^{\circ} C ; V_{8} \text { rất thấp và } \\
V_{13} \text { cao. }(11 / 08 / 2016)\end{array}$ \\
\hline 5 & 30 & $\begin{array}{l}1,12 / \\
73,63 / 1,37\end{array}$ & $\begin{array}{l}0,43 / \\
0,263 \\
\end{array}$ & $\begin{array}{l}0,43 / \\
0,248\end{array}$ & $\begin{array}{ll}0,419 / \\
0,18\end{array}$ & $\begin{array}{l}0,408 / \\
0,126\end{array}$ & $\begin{array}{l}0,421 / \\
\mathbf{0 , 2 0 4} \\
\end{array}$ & $\begin{array}{l}\mathrm{t}_{\text {lim }}=-17^{\circ} \mathrm{C} ; \mathrm{V}_{8} \text { thấp và } \mathrm{V}_{13} \\
\text { thấp. }(31 / 07 / 2016)\end{array}$ \\
\hline 6 & 30 & $\begin{array}{l}0,94 / \\
84,47 / 1,35\end{array}$ & $\begin{array}{l}0,445 / \\
0,246\end{array}$ & $\begin{array}{l}0,434 / \\
0,204\end{array}$ & $\begin{array}{l}0,421 / \\
0,202\end{array}$ & $\begin{array}{l}0,416 / \\
0,193\end{array}$ & $\begin{array}{l}0,429 / \\
\mathbf{0 , 2 1} \\
\end{array}$ & $\begin{array}{l}\mathrm{t}_{\mathrm{lim}}=-17,5^{\circ} C ; \mathrm{V}_{8} \text { rất thấp và } \\
\mathrm{V}_{13} \text { cao. }(28 / 07 / 2016)\end{array}$ \\
\hline 7 & 31 & $\begin{array}{l}1,1 / 79,3 / \\
1,31\end{array}$ & $\begin{array}{l}0,432 / \\
0,263\end{array}$ & $\begin{array}{l}0,421 / \\
0,21\end{array}$ & $\begin{array}{l}0,415 / \\
0,201\end{array}$ & $\begin{array}{l}0,404 / \\
0,228\end{array}$ & $\begin{array}{l}0,418 / \\
\mathbf{0 , 2 1}\end{array}$ & $\begin{array}{l}\mathrm{t}_{\text {lim }}=-18^{\circ} C ; \mathrm{V}_{8} \text { thấp và } \mathrm{V}_{13} \\
\text { thấp. }(14 / 07 / 2016)\end{array}$ \\
\hline 8 & 31 & $\begin{array}{l}0,81 / \\
97,32 / 1,33\end{array}$ & $\begin{array}{l}0,452 / \\
0,298 \\
\end{array}$ & $\begin{array}{l}0,445 / \\
0,26 \\
\end{array}$ & $\begin{array}{l}0,428 / \\
0,12\end{array}$ & $\mathrm{x}$ & $\begin{array}{l}0,442 / \\
\mathbf{0 , 2 2 6} \\
\end{array}$ & $\begin{array}{l}\mathrm{t}_{\text {lim }}=-8^{\circ} C ; \mathrm{V}_{8} \text { thấp và } \mathrm{V}_{13} \\
\text { rất cao. }(15 / 07 / 2016)\end{array}$ \\
\hline 9 & 31 & $\begin{array}{l}2,27 / 72,9 / \\
2,65\end{array}$ & $\begin{array}{l}0,412 / \\
0,308 \\
\end{array}$ & $\begin{array}{l}0,399 / \\
0,238 \\
\end{array}$ & $\begin{array}{l}0,393 / \\
0,212\end{array}$ & $\begin{array}{l}0,389 / \\
0,102\end{array}$ & $\begin{array}{ll}0,398 / \\
\mathbf{0 , 2 1 5} \\
\end{array}$ & $\begin{array}{l}\mathrm{t}_{\text {lim }}=-17,5^{\circ} C ; \mathrm{V}_{8} \text { cao và } \mathrm{V}_{13} \\
\text { thấp. }(19 / 07 / 2016)\end{array}$ \\
\hline 10 & 31 & $\begin{array}{l}0,78 / \\
77,75 / 1,21\end{array}$ & $\begin{array}{l}0,438 / \\
0,34\end{array}$ & $\begin{array}{l}0,444 / \\
0,321\end{array}$ & $\begin{array}{l}0,437 / \\
0,289\end{array}$ & $\begin{array}{l}0,425 / \\
0,097\end{array}$ & $\begin{array}{l}0,436 / \\
\mathbf{0 , 2 6 2}\end{array}$ & $\begin{array}{l}\mathrm{t}_{\text {lim }}=-18^{\circ} C ; \mathrm{V}_{8} \text { trung bình } \\
\text { và } \mathrm{V}_{13} \text { trung bình phù hợp. } \\
(23 / 07 / 2016)\end{array}$ \\
\hline 11 & 31 & $\begin{array}{l}1,83 / 96,8 \\
12,1\end{array}$ & $\begin{array}{l}0,434 / \\
0,307\end{array}$ & $\begin{array}{l}0,426 / \\
0,272\end{array}$ & $\begin{array}{l}0,424 / \\
0,204\end{array}$ & $\begin{array}{l}0,412 / \\
0,149\end{array}$ & $\begin{array}{l}0,424 / \\
0,233\end{array}$ & $\begin{array}{l}\mathrm{t}_{\text {lim }}=-15^{\circ} C ; \mathrm{V}_{8} \text { trung bình } \\
\text { và } \mathrm{V}_{13} \text { cao. }(25 / 07 / 2016)\end{array}$ \\
\hline 12 & 32,5 & $\begin{array}{l}0,99 / 66 / \\
1,2\end{array}$ & $\begin{array}{l}0,429 / \\
0,173 \\
\end{array}$ & $\begin{array}{l}0,426 / \\
0,131 \\
\end{array}$ & $\begin{array}{l}0,413 / \\
0,102\end{array}$ & $\mathrm{x}$ & $\begin{array}{l}0,423 / \\
\mathbf{0 , 1 3 5}\end{array}$ & $\begin{array}{l}\mathrm{t}_{\text {lim }}=-7^{\circ} C ; \mathrm{V}_{8} \text { thấp và } \mathrm{V}_{13} \\
\text { rất thấp. }(12 / 08 / 2016)\end{array}$ \\
\hline 13 & 32,5 & $\begin{array}{l}2,13 / \\
61,86 / 2,3\end{array}$ & $\begin{array}{l}0,329 / \\
0,156 \\
\end{array}$ & $\begin{array}{l}0,314 / \\
0,106 \\
\end{array}$ & $\begin{array}{l}0,318 / \\
0,091\end{array}$ & $\mathrm{x}$ & $\begin{array}{l}0,32 / \\
\mathbf{0 , 1 1 9} \\
\end{array}$ & $\begin{array}{l}\mathrm{t}_{\text {lim }}=-6^{\circ} C ; \mathrm{V}_{8} \text { cao và } \mathrm{V}_{13} \text { rất } \\
\text { thấp. }(13 / 08 / 2016)\end{array}$ \\
\hline 14 & 32 & $\begin{array}{l}1,81 / 65,3 / \\
1,91\end{array}$ & $\begin{array}{l}0,369 / \\
0,22\end{array}$ & $\begin{array}{l}0,368 / \\
0,161\end{array}$ & $\begin{array}{ll}0,364 / \\
0,155\end{array}$ & $\begin{array}{l}0,358 / \\
0,071\end{array}$ & $\begin{array}{l}0,365 / \\
\mathbf{0 , 1 5 4}\end{array}$ & $\begin{array}{l}\mathrm{t}_{\text {lim }}=-14^{\circ} C ; \mathrm{V}_{8} \text { cao và } \mathrm{V}_{13} \\
\text { rất thấp. }(17 / 08 / 2016)\end{array}$ \\
\hline
\end{tabular}

Theo bảng 2, nồng độ khối lượng dung dịch $\mathrm{NH}_{3}-\mathrm{H}_{2} \mathrm{O}$ nạp trong phạm vi từ $29,5 \%$ đến $32,5 \%$. Các thí nghiệm được thực hiện trên máy lạnh hấp thụ hoàn chỉnh và hoạt động ổn định. Các đồ thị biểu diễn mối quan hệ của $\mathrm{COP}$ và $\mathrm{COP}_{\mathrm{u}}$ với nhiệt độ, nồng độ theo thời gian của 14 thí nghiệm để tìm nồng độ nạp phù hợp nhất của dung dịch $\mathrm{NH}_{3}-\mathrm{H}_{2} \mathrm{O}$ theo điều kiện nhiệt độ nước giải nhiệt $\mathrm{t}_{\mathrm{c}}\left({ }^{\circ} \mathrm{C}\right), \mathrm{t}_{\mathrm{a}}\left({ }^{\circ} \mathrm{C}\right)$; và theo nhiệt độ bay hơi yêu cầu $t_{\mathrm{e}}\left({ }^{\circ} \mathrm{C}\right)$. Ký hiệu $\mathrm{x}$ là trong khoảng nhiệt độ âm yêu cầu đó máy không đạt được. ký hiệu “<<" (như: “- $9^{\circ} \mathrm{C}<<-18^{\circ} \mathrm{C} ", \ldots$ ) là trong khoảng nhiệt độ âm yêu cầu để làm nước đá từ 0 đến $-18^{\circ} \mathrm{C}$ thì $-9^{\circ} \mathrm{C}$ là còn rất nhỏ so với $-18^{\circ} \mathrm{C}$ yêu cầu.

Theo thí nghiệm $7,8,9,10$, và 11 , nồng độ dung dịch nạp là $31 \%$. Dòng dung dịch loãng trung bình từ bình phát sinh vào bộ hấp thụ $\mathrm{V}_{8}=0,78 \div 2,27 \mathrm{l} / \mathrm{p}$. Dòng hơi $\mathrm{NH}_{3}$ từ bộ bay hơi vào bộ hấp thụ được điều chỉnh $\mathrm{V}_{13}=72,9 \div 97,32 \mathrm{l} / \mathrm{p}$. Theo $\mathrm{TN} 8$, dòng dòng hơi $\mathrm{NH}_{3}$ từ bộ bay hơi vào bộ hấp thụ được điều chỉnh $\mathrm{V}_{13}=$ $97,32 \mathrm{l} / \mathrm{p}$ rất cao so với dòng dung dịch loãng trung bình từ bình phát sinh vào $\mathrm{V}_{8}=0,81 \mathrm{l} / \mathrm{p}$. Vì thế, hơi $\mathrm{NH}_{3}$ không được hấp thụ hết làm tăng áp suất hấp thụ, dẫn đến áp suất bay hơi tăng. Hiệu suất nhiệt của máy lạnh hấp thụ $\mathrm{COP}=0,442$ và hiệu suất làm lạnh nước muối $\mathrm{COP}_{\mathrm{u}}=0,226$, nhiệt độ nước muối giới hạn $t_{\lim }=-9^{\circ} \mathrm{C}<<-18^{\circ} \mathrm{C}$. Theo $\mathrm{TN} 1$, hiệu suất nhiệt của máy lạnh hấp thụ $\mathrm{COP}=0,4$ và hiệu suất làm lạnh nước muối $\mathrm{COP}_{\mathrm{u}}=0,178$ là thấp, nhiệt độ nước muối giới hạn $-8{ }^{\circ} \mathrm{C}<<-18{ }^{\circ} \mathrm{C}$ không thỏa yêu cầu nhiệt độ làm nước đá. Theo TN7 $\left(\mathrm{V}_{8}=1,1 \mathrm{l} / \mathrm{p} ; \mathrm{V}_{13}=79,3 \mathrm{l} / \mathrm{p}\right)$ và $\mathrm{TN} 9\left(\mathrm{~V}_{8}=2,27 \mathrm{l} / \mathrm{p} ; \mathrm{V}_{13}=72,9 \mathrm{l} / \mathrm{p}\right)$ là cao, làm cho công suất nhiệt cấp bị thiếu. Vì thế, hiệu suất làm lạnh nước muối thấp lần lượt là $\mathrm{COP}_{\mathrm{u}}=0,21$ và $\mathrm{COP}_{\mathrm{u}}$ $=0,215$. 


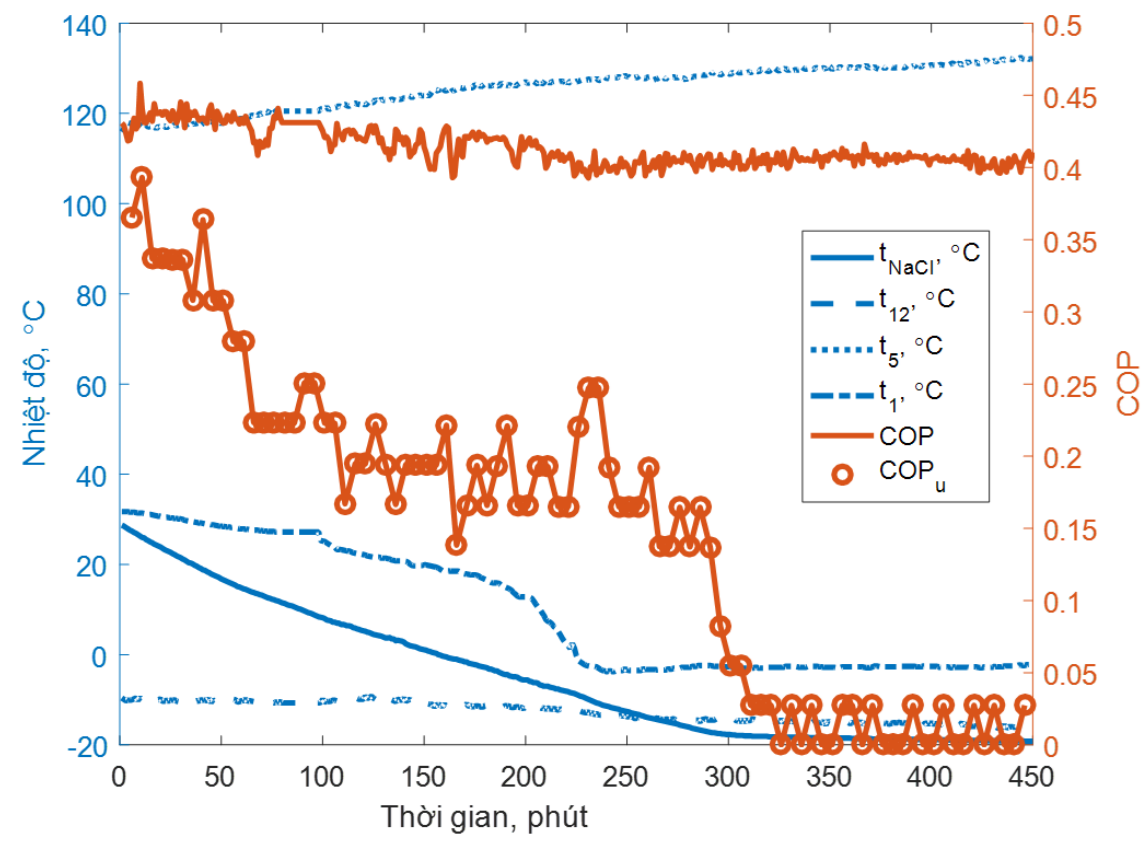

Hình 3: Nhiệt độ, COP theo thí nghiệm 7

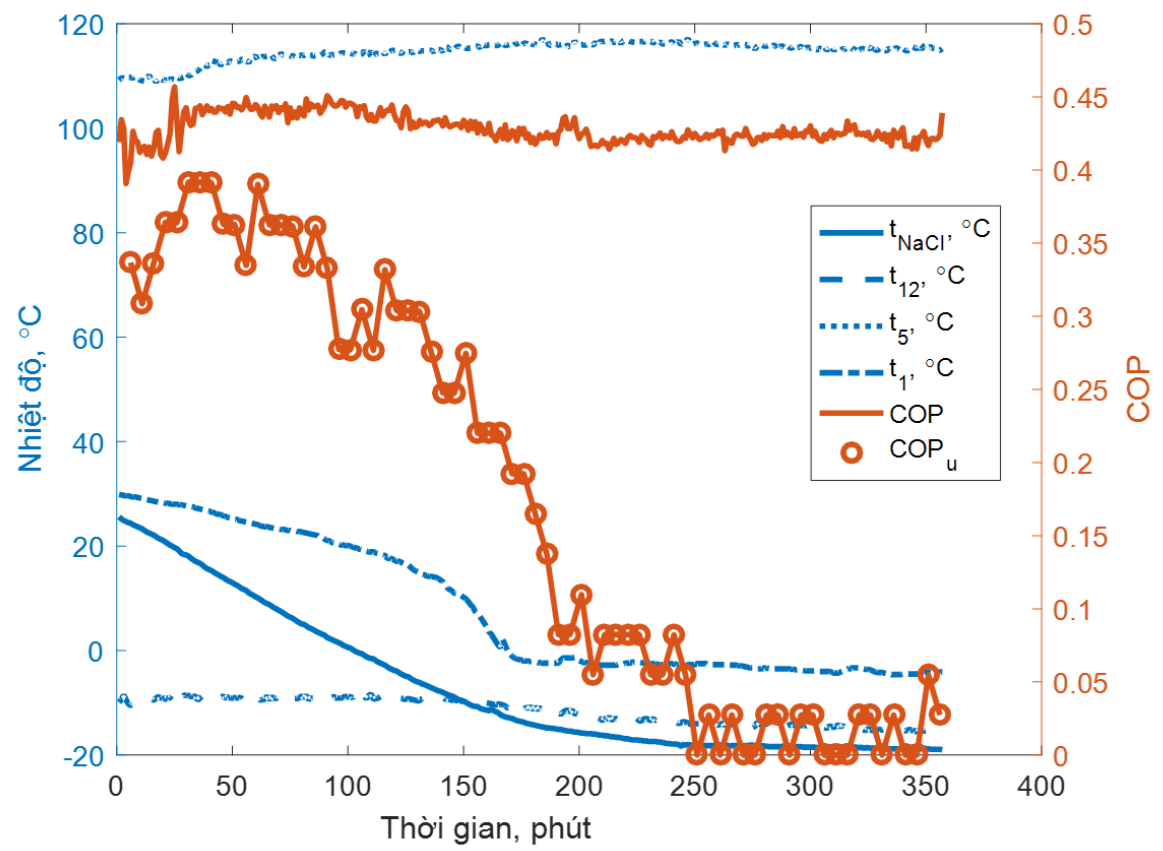

Hình 5: Nhiệt độ, COP theo thí nghiệm 10

Theo TN7, hiệu suất nhiệt của máy lạnh hấp thụ $\mathrm{COP}=0,419$ và hiệu suất làm lạnh nước muối $\mathrm{COP}_{\mathrm{u}}=$ 0,21 là thấp nhất; nhiệt độ nước muối giới hạn $\mathrm{t}_{\mathrm{lim}}=-18^{\circ} \mathrm{C}$. Theo $\mathrm{TN} 10$, hiệu suất nhiệt của máy lạnh hấp thụ $\mathrm{COP}=0,436$ và hiệu suất làm lạnh nước muối $\mathrm{COP}_{\mathrm{u}}=0,262$ đạt cao nhất; nhiệt độ nước muối giới hạn $\mathrm{t}_{\mathrm{lim}}=-18^{\circ} \mathrm{C}$. Nồng độ dung dịch nạp là $\mathrm{C}_{\mathrm{i}}=31 \%$ là phù hợp. Hình 4 và 5 trình bày lần lượt hiệu suất nhiệt của máy lạnh hấp thụ $\mathrm{COP}$ và hiệu suất làm lạnh nước muối $\mathrm{COP}_{\mathrm{u}}$ của TN7 và TN10.

Hiệu suất nhiệt của máy lạnh hấp thụ $\mathrm{COP}$ cao hơn hiệu suất làm lạnh nước muối $\mathrm{COP}_{\mathrm{u}}$ khoảng $40 \%$ ((0.436-0.262)/0.436), nghĩa là khả năng tăng $\mathrm{COP}_{u}$ lên thêm được $40 \%$ nữa nhờ vào bọc cách nhiệt tốt hơn để tránh tổn thất ra môi trường ở các bộ phận, nhất là bộ phận làm nước đá. 


\section{3 Đánh giá độ ổn định}

Để có chế độ vận hành ổn định, nguồn nhiệt phải đáp ứng cho dung dịch $\mathrm{NH}_{3}-\mathrm{H}_{2} \mathrm{O}$ sôi ở nhiệt độ ổn định theo điều kiện môi trường giải nhiệt, nhiệt độ làm lạnh yêu cầu, và công suất lạnh gọi là nhiệt độ vận hành phù hợp.

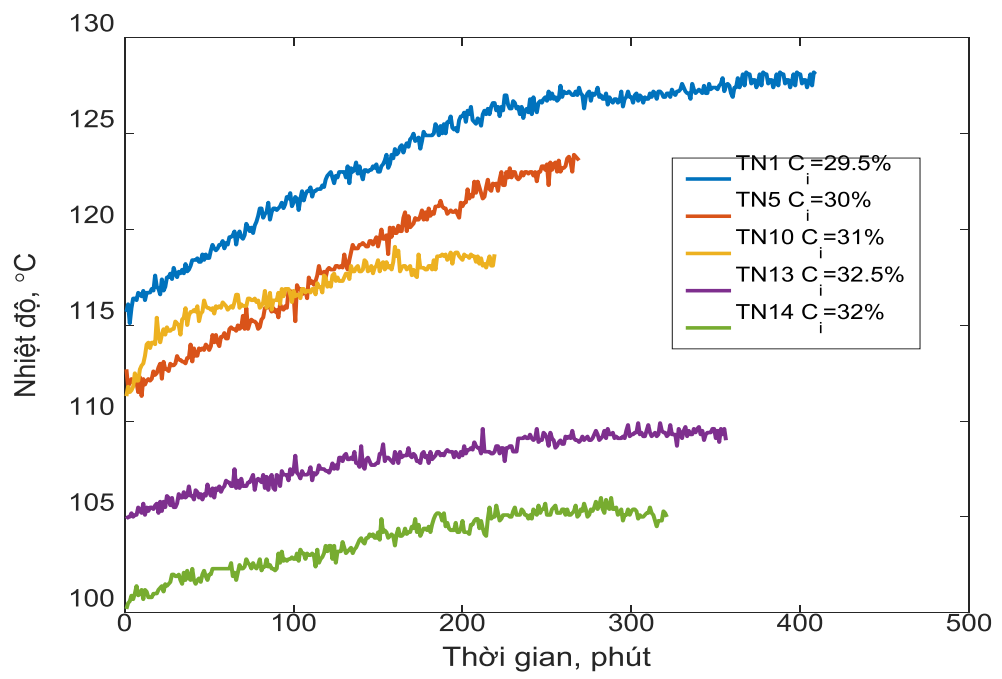

Hình 6: Nhiệt độ hơi $\mathrm{NH}_{3}$ ra khỏi bình phát sinh (t5)

Nhiệt độ trung bình của hơi $\mathrm{NH}_{3}$ rời khỏi bình phát sinh $\mathrm{t}_{5}$ theo các thí nghiệm từ $1,6,10,13,14$ lần lượt là 124,$2 ; 118,2 ; 116,6 ; 107,7 ; 103,7\left({ }^{\circ} \mathrm{C}\right)$. Nhiệt độ của hơi $\mathrm{NH}_{3}$ rời khỏi bình phát sinh $\mathrm{t}_{5}$ theo thí nghiệm 1 tăng nhiều nhất và lớn nhất là do công suất lạnh sử dụng đang được điều chỉnh ở chế độ thấp hơn công suất nhiệt cấp vào. Ở thí nghiệm 10 , dòng hơi $\mathrm{NH}_{3}$ và dòng dung dịch lỏng phù hợp và vừa đủ so với công suất nhiệt cấp vào của bình phát sinh nên hệ số hiệu quả của máy lạnh $\mathrm{COP}=0,436$ và hệ số hiệu quả làm nước đá $\mathrm{COP}_{\mathrm{u}}=0,262$ đều đạt cao nhất. Quan sát hình 6 , nhiệt độ dòng hơi $\mathrm{NH}_{3}$ ra khỏi bình phát sinh $\mathrm{t}_{5} \mathrm{O}^{\circ}$ thí nghiệm 10 tăng nhẹ cho đến khi nhiệt độ nước muối đạt nhiệt độ giới hạn $\mathrm{t}_{\mathrm{NaCl}}=-18^{\circ} \mathrm{C}$.

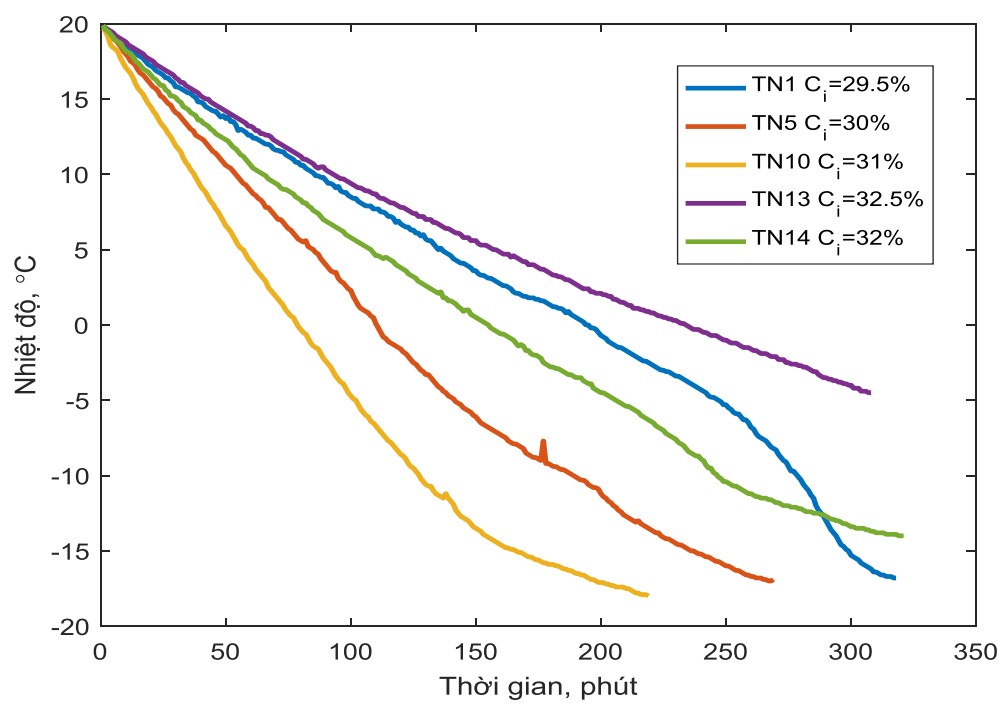

Hình 7: Nhiệt độ dung dịch nước muối

Như được trình bày ở hình 7 , nhiệt độ nước muối giới hạn $\mathrm{t}_{\text {lim }}$ theo thí nghiệm $1,6,10,13,14$ lần lượt là $17,-17,5,-18,-6,-14\left({ }^{\circ} \mathrm{C}\right)$. Nồng độ nạp phù hợp là phải đảm bảo cho hệ thống làm việc ổn định, đạt được điều kiện của nhiệt độ làm nước đá $\mathrm{t}_{\lim }=-18^{\circ} \mathrm{C}$, và đạt hiệu suất làm nước đá cao nhất $\mathrm{COP}=0,436, \mathrm{COP}$ $=0,262$ (theo thí nghiệm $10, \mathrm{C}_{\mathrm{i}, \mathrm{opt}}=31 \%$ ). 
Theo thí nghiệm 13, nồng độ dung dịch $\mathrm{NH}_{3}-\mathrm{H}_{2} \mathrm{O}$ nạp $\left(\mathrm{C}_{\mathrm{i}}=32,5 \%\right)$ cao thì nhiệt độ phát sinh sẽ thấp. Nếu lưu lượng dung dịch loãng $\mathrm{NH}_{3}-\mathrm{H}_{2} \mathrm{O}$ lớn và lưu lượng dòng hơi $\mathrm{NH}_{3}$ vào bộ hấp thụ được điều chỉnh tương ứng theo lưu lượng dung dịch loãng. Lượng dung dịch đặc quay về bình phát sinh nhiều làm giảm nhiệt độ phát sinh, làm giảm hiệu suất của máy. Nếu Nếu lưu lượng dung dịch loãng $\mathrm{NH}_{3}-\mathrm{H}_{2} \mathrm{O}$ nhỏ thì hơi $\mathrm{NH}_{3}$ được hấp thụ vào dung dịch loãng trong bộ hấp thụ rất ít.

Theo thí nghiệm 1, nồng độ dung dịch $\mathrm{NH}_{3}-\mathrm{H}_{2} \mathrm{O}$ nạp $\left(\mathrm{C}_{\mathrm{i}}=29,5 \%\right)$ thấp thì nhiệt độ phát sinh sẽ cao. Nếu lưu lượng dung dịch loãng $\mathrm{NH}_{3}-\mathrm{H}_{2} \mathrm{O}$ lớn và lưu lượng dòng hơi $\mathrm{NH}_{3}$ vào bộ hấp thụ được điều chỉnh tương ứng theo lưu lượng dung dịch loãng. Lượng dung dịch đặc quay về bình phát sinh nhiều làm giảm nhiệt độ phát sinh, làm giảm hiệu suất của máy. Nếu lưu lượng dung dịch loãng $\mathrm{NH}_{3}-\mathrm{H}_{2} \mathrm{O}$ quá nhỏ thì máy sẽ dễ rơi vào tình trạng làm việc không ổn định.

Khi nồng độ dung dịch nạp cao thì nhiệt độ phát sinh sẽ thấp, tổn thất nhiệt của máy lạnh giảm. Quá trình sinh hơi $\mathrm{NH}_{3}$ trong bình phát sinh rất tốt và kéo theo ít $\mathrm{H}_{2} \mathrm{O}$, tổn thất nhiệt cho cột chiết tách giảm. Nhưng dòng hơi $\mathrm{NH}_{3}$ được hấp thụ bởi dung dịch loãng trong bộ hấp thụ rất ít làm áp suất bộ hấp thụ tăng dẫn đến áp suất bay hơi tăng. Nhiệt độ bay hơi không thể giảm xuống thấp theo điều kiện làm nước đá $t_{\text {lim }}=-18^{\circ} \mathrm{C}$. Hiệu suất bay hơi của $\mathrm{NH}_{3}$ trong bộ bay hơi giảm nên $\mathrm{COP}_{\mathrm{u}}$ giảm. Trường hợp này, máy lạnh làm việc rất ổn định vì nhiệt độ phát sinh luôn đáp ứng để sinh hơi. Hiệu suất làm nước đá rất thấp vì dòng hơi $\mathrm{NH}_{3}$ được hấp thụ bởi dung dịch loãng trong bộ hấp thụ rất ít.

Khi nồng độ dung dịch nạp thấp, nhiệt độ phát sinh sẽ cao, tổn thất nhiệt của máy lạnh tăng. Nhưng sự hấp thụ hơi $\mathrm{NH}_{3}$ vào dung dịch loãng trong bộ hấp thụ rất tốt. Quá trình sinh hơi $\mathrm{NH}_{3}$ trong bình phát sinh kéo theo nhiều $\mathrm{H}_{2} \mathrm{O}$, tổn thất nhiệt cho cột chiết tách tăng, và hiệu suất bay hơi của $\mathrm{NH}_{3}$ trong bộ bay hơi giảm nên $\mathrm{COP}$ và $\mathrm{COP}_{\mathrm{u}}$ giảm. Trường hợp này, máy lạnh dễ mất ổn định vì dễ xảy ra hiện tượng nhiệt độ phát sinh giảm nếu công suất nhiệt cấp cho bình phát sinh không đảm bảo.

\section{KẾT LUẦN}

Đã thực hiện các thí nghiệm trên bộ hấp thụ kiểu màng chảy trên chùm ống nằm ngang được gắng vào máy lạnh hấp thụ hoàn chỉnh:

○ Bộ hấp thụ chế tạo có công suất lạnh $2 \mathrm{~kW}$ hoạt động ổn định có thể sản xuất mẻ đá $8 \mathrm{~kg}$ trong 2 giờ.

- Theo các thí nghiệm, nhiệt độ giới hạn của nước muối đạt khoảng $-18^{\circ} \mathrm{C}$ và lưu lượng dung dịch loãng từ bình phát sinh vào bộ hấp thụ $\mathrm{V}_{8}=0,78 \mathrm{l} / \mathrm{p}$ và hơi từ bộ bay hơi vào bộ hấp thụ $\mathrm{V}_{13}=$ $77,75 \mathrm{l} / \mathrm{p}$ được điều chỉnh theo công suất cấp nhiệt từ bình phát $\sinh \mathrm{Q}_{\mathrm{g}}=3,76 \mathrm{~kW}$. Chế độ phù hợp nhất để sản xuất nước đá là ở thí nghiệm 10 có hệ số hiệu quả máy $\mathrm{COP}=0,436$ và hiệu suất làm nước đá $\mathrm{COP}_{\mathrm{u}}=0,262$; nhiệt độ trung bình của hơi ra khỏi bình phát sinh khoảng $\mathrm{t}_{5}=116,5^{\circ} \mathrm{C}$; với nồng độ dung dịch $\mathrm{NH}_{3}-\mathrm{H}_{2} \mathrm{O}$ nạp phù hợp là $31 \%$.

\section{TÀI LIẸU THAM KHẢO}

[1] J. D. Killion and S. Garimella, "A critical review of models of coupled heat and mass transfer in falling-film absorption," International Journal of Refrigeration, vol. 24, pp. 755-797, 12// 2001.

[2] W. A. Miller, "The Experimental Analysis of Aqueous Lithium Bromide Vertical Film Absorption," Doctor of Philosophy, Mechanical Engineering, University of Tennessee - Knoxville, 1998.

[3] N. P. Minh. "Energy and exergy estimation for a combined cycle of solid CO2 production and NH3-H2O single effect absorption chiller." Science and Technology Development Journal 19, no. 1 (2016): 61-69.

[4] K. B. Lee, B. H. Chun, J. C. Lee, J. C. Hyun, and S. H. Kim, "COMPARISON OF HEAT AND MASS TRANSFER IN FALLING FILM AND BUBBLE ABSORBERS OF AMMONIA-WATER," Experimental Heat Transfer, vol. 15, pp. 191-205, 2002/07/01 2002.

[5] Y. Tae Kang, A. Akisawa, and T. Kashiwagi, "Analytical investigation of two different absorption modes: falling film and bubble types," International Journal of Refrigeration, vol. 23, pp. 430-443, 9// 2000. 
[6] A. A. Kang YT, Kashiwagi T, "Experimental correlation of combined heat and mass transfer for NH3-H2O falling film absorption," Int. J. Refrigeration, pp. 250-262, 1999.

[7] M. R. Islam, "Absorption process of a falling film on a tubular absorber: An experimental and numerical study," Applied Thermal Engineering, vol. 28, pp. 1386-1394, 8// 2008.

[8] S. Garimella, M. D. Determan, J. M. Meacham, S. Lee, and T. C. Ernst, "Microchannel component technology for system-wide application in ammonia/water absorption heat pumps," International Journal of Refrigeration, vol. 34, pp. 1184-1196, 8// 2011.

[9] N. Goel and D. Y. Goswami, "A Compact Falling Film Absorber," Journal of Heat Transfer, vol. 127, pp. 957965, 2005.

[10] N. A. Darwish, S. H. Al-Hashimi, and A. S. Al-Mansoori, "Performance analysis and evaluation of a commercial absorption-refrigeration water-ammonia (ARWA) system," International Journal of Refrigeration, vol. 31, pp. 12141223, 11// 2008.

[11] M. Aneke, B. Agnew, C. Underwood, and M. Menkiti, "Thermodynamic analysis of alternative refrigeration cycles driven from waste heat in a food processing application," International Journal of Refrigeration, vol. 35, pp. $1349-1358,8 / / 2012$

[12] B. Le Lostec, N. Galanis, and J. Millette, "Experimental study of an ammonia-water absorption chiller," International Journal of Refrigeration, vol. 35, pp. 2275-2286, 12// 2012

[13] M. Ozgoren, M. Bilgili, and O. Babayigit, "Hourly performance prediction of ammonia-water solar absorption refrigeration," Applied Thermal Engineering, vol. 40, pp. 80-90, 7// 2012

[14] M. S. v. S. P. Weihua Cai, "Dynamic simulation of an ammonia-water absorption refrigeration system," Department of Aerospace and Mechanical Engineering University of Notre Dame, Notre Dame, 2010.

[15] A. J. G. Linghui Zhu, "Thermodynamic analysis of a novel thermal driven refrigeration system," World Academy of Science, Engineering and Technology vol. 322009

[16] J. Fernández-Seara and M. Vázquez, "Study and control of the optimal generation temperature in NH3-H2O absorption refrigeration systems," Applied Thermal Engineering, vol. 21, pp. 343-357, 2/1/ 2001.

[17] M. C. ENGINEERING, Thermophysical Properties of NH3 H2O Mixtures for the Industrial Design of Absorption Refrigeration Equipment, 2004.

[18] P. N. Minh. "Overall optimization and exergy analysis of an air conditioning system using a series-series counterflow arrangement of water chillers." International Journal of Air-Conditioning and Refrigeration 27, no. 04 (2019): 1950034.

[19] P. N. Minh, and G. S. Lee. "Characteristics of pressure and force considering friction in a closed cylinder with a holed piston." Journal of Mechanical Science and Technology 28, no. 6 (2014): 2409-2415.

[20] K. S. a. M. A. A. J. M. Abdulateef, "Optimum design for solar absorption refrigeration systems and comparison of the performances using ammonia-water, ammonia-lithium nitrate and ammonia-sodium thiocyanate solutions," International Journal of Mechanical and Materials Engineering (IJMME), vol. Vol. 3 pp. 17-24, 2008.

[21] I. K. L. Version 1 ME, "Vapour Absorption Refrigeration Systems Based On Ammonia-Water Pair," ed.

Ngày nhận bài: 17/03/2021

Ngày chấp nhận đăng: 17/05/2021 